\title{
APOLOGIA À OBRA A CONDIÇÃo HUMANA dE HANNAH ARENDT 60 ANOS APÓS SUA PRIMEIRA PUBLICAÇÃo
}

\section{[Apology to Hannah ARENDT'S The human CONDITION 60 YEARS AFTER ITS FIRST EDITION]}

Maria Cristina Müller

Professora do Depto. de Filosofia da Universidade Estadual de Londrina Coordenadora do GT Filosofia Política Contemporânea da ANPOF

DOI: http://dx.doi.org/10.21680/1983-2109.2018v25n48ID14139

Natal, v. 25, n. 48

Set.-Dez. 2018, p. 31-58

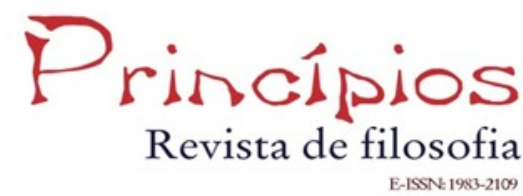


Resumo: Indaga-se acerca da atualidade da obra A condição humana de Hannah Arendt, tendo como referência as incompreensões que provocou. Objetiva-se apresentar a obra relacionando-a com os demais escritos de Arendt apontando para a relevância de se alinhavar os conceitos de $A$ condição humana com outros escritos de Arendt, principalmente a partir da crítica à tradição do pensamento político. A principal indagação é: o que Arendt almeja? Decorrem dela outras questões, como pano de fundo, motivações, propósitos, tema e método. A pesquisa é bibliográfica e utiliza como procedimentos a leitura, análise, compreensão e reconstrução teórica das obras de Arendt e de seus comentadores. Assinala-se a atualidade da crítica de Arendt ao mundo moderno e a alienação dos homens e mulheres que o compõem; a política foi derrotada pela urgência das necessidades da vida e o advento do social sobre a política levou ao declínio do domínio público. Tais problemas permanecem e se agravaram, portanto, a obra de Arendt continua perene. Isto permite asseverar a atualidade da obra de Arendt 60 anos depois de sua reflexão acerca do que estamos fazendo no mundo.

Palavras-chave: Arendt; A condição humana; Apologia; Crítica; Atualidade.

Abstract: We analyze the actuality of Hannah Arendt's The human condition having as reference the incomprehension that it provoked. We aim to present the work in relation to the other writings of Arendt highlighting the relevance of aligning the concepts of The human condition with these, starting from her critique of the tradition of political thought. The main question is: what does Arendt want? Other questions arise from this, such as background, motivations, purposes, theme, and method. The research is bibliographical and uses reading, analysis, comprehension and the theoretical reconstruction of the works of Arendt and her commentators as procedures. We point at the relevance of Arendt's critique of the modern world and the alienation of the men and women who comprise it. The urgency of life's needs has defeated politics and the advent of social policy led to the decline of the public domain. Such problems still remain and become worse, and therefore Arendt's work persists. Hence, it's possible to ascertain the actuality of Arendt's work 60 years after her reflection on what we are doing in the world.

Keyworks: Arendt; The human condition; Apology; Criticism; Present. 
Os 60 anos de publicação da obra $A$ condição humana de Hannah Arendt motivam a presente reflexão e indaga-se a atualidade da obra, tendo como pano de fundo as incompreensões que provocou. As indagações que o presente artigo aspira esclarecer e que orientam a revisão da bibliografia se relacionam com essas incompreensões e as dificuldades enfrentadas pelos leitores da obra $A$ condição humana, principalmente ao se depararem com o prólogo. O prólogo apresenta, como provocação para as discussões dos capítulos seguintes, dois eventos enigmáticos, frutos do desenvolvimento da ciência e da técnica: o lançamento de um satélite artificial na órbita da Terra e o advento da automação. A questão que se coloca ao leitor é entender de que maneira os dois eventos apresentados no prólogo auxiliam a compreensão da condição humana e das atividades da vida ativa. A principal indagação que toma de assalto o leitora partir do prólogo é saber o que Arendt almeja realizar em $A$ condição humana. A partir dessa indagação, mais geral, outras perguntas decorrem: qual é o pano de fundo das discussões apresentadas por Arendt em $A$ condição humana? Quais são as motivações que levam Arendt à reconstrução das atividades humanas? Qual é seu propósito? Qual é o tema a guiar sua reflexão? Qual é o método que orienta a elaboração do escrito? Qual é a relação de $A$ condição humana com a obra completa de Arendt? O que a obra ainda pode dizer de relevante no século XXI? Almeja-se, a partir disto, retraçar os objetivos de Arendt, relacionando as principais discussões expostas por ela nesta obra com os demais escritos da autora. A hipótese que guia a reflexão consiste na relevância de se alinhavar os conceitos de $A$ condição humana com outros escritos de Arendt, principalmente a partir da crítica que ela dirige à tradição do pensamento político. Para tanto se procede a uma pesquisa bibliográfica que utiliza como procedimentos a leitura, análise, compreensão e reconstrução teórica das obras de Hannah Arendt e dos seus comentadores. 
Assinala-se a atualidade da crítica de Arendt ao mundo moderno e a alienação dos homens e mulheres que o compõem; a política foi derrotada pela urgência das necessidades da vida e o advento do social sobre o político levou ao enfraquecimento e declínio do domínio público. Tais problemas permanecem e até mesmo se agravam: a intimidade é cada vez mais exposta e o relevante, aquilo que efetivamente deveria ser colocado em disputa pública, é deixado para trás. Isto permite asseverar a atualidade da obra de Arendt 60 anos depois de sua reflexão acerca do que estamos fazendo no mundo.

Inicialmente será apresentada a obra $A$ condição humana, sua publicação, recepção e algumas das percepções de importantes comentadores. Em seguida, tendo como ponto de partida o prólogo, serão enunciados os propósitos, as motivações, o pano de fundo e o método, até chegar à definição do tema geral de $A$ condição humana. Todas essas referências serão alinhavadas com outras obras de Arendt. Por fim, será demonstrada a relevância perene da obra A condição humana 60 anos depois da sua publicação, incluindo a recepção no Brasil.

\section{Apologia à obra $A$ condição humana}

A condição humana foi publicada nos EUA em 1958, após Origens do Totalitarismo (1951). É a obra de Arendt mais conhecida do grande público e pela qual recebeu o devido reconhecimento e notoriedade. Isto se confirma pelo fato de ter sido necessária uma reedição do livro quatro meses após a publicação. Além disto, seguiram-se inúmeros convites para conferências e solicitações de entrevistas para a televisão. Arendt, em carta $^{1}$ a Jaspers, esclarece que ninguém, sequer o editor, sabia explicar o motivo do êxito nas vendas do livro.

\footnotetext{
${ }^{1}$ Carta ${ }^{\circ}$ 233, de 16 de novembro de 1958, encontrada na Correspondência entre Hannah Arendt e Karl Jaspers (Arendt; Jaspers, 1992, p. 356 -358).
} 
A obra é publicada em 1960 na Alemanha sob o título que Arendt originalmente pretendia ao livro, isto é, Vita activa ${ }^{2}$ (Vita activa: oder von tätiger Leben). A própria Arendt se encarregou da tradução para o alemão e realizou algumas revisões e correções; pode-se dizer que o reescreveu. Em 1961 a obra é traduzida para o francês e publicada, e, em 1983, por ocasião da segunda edição, recebeu prefácio de Paul Ricœur. Na Espanha o livro é publicado pela primeira vez em 1974; em 1993 as Ediciones Paidós publicam uma reedição com introdução de Manuel Cruz. No Brasil a primeira edição é de 1981, com posfácio - "A política e a condição humana" - de Celso Lafer (1981, p. 340-351); em 2010, Adriano Correia revisa a tradução e redige a nova apresentação da obra, que estava na $11^{\mathrm{a}}$ edição. Em 1998 é publicada uma nova edição americana, o que coincide com o $40^{\circ}$ ano da publicação original; tal edição contém uma importante introdução de Margaret Canovan (2016, p. LI-LXVII), incluída em 2016 na 13ª edição brasileira.

Muitas são as interpretações que $A$ condição humana suscita; muitas são as discussões que Arendt expõe na obra. Deste modo, é difícil reduzi-la a um único tema ou abarcar a totalidade das discussões em uma única leitura. Mais problemático é tentar encontrar na obra análises panorâmicas, verdades prontas e um manual de prescrições políticas ou doutrinas, pretensões comuns àqueles acostumados a um tipo de pensamento que apenas observa o mundo de um lugar elevado, a uma filosofia política ávida em propor concepções com pretensão de verdade e àqueles que buscam guias que possam conduzir ou salvar suas vidas e o mundo.

É possível especular que as críticas mais impertinentes que recebeu e as incompreensões que provocou possam advir da ignorância em relação ao entendimento que Arendt possuía da

\footnotetext{
${ }^{2}$ Carta $\mathrm{n}^{\circ}$ 183, de 7 de abril de 1956, encontrada na Correspondência entre Hannah Arendt e Karl Jaspers (Arendt; Jaspers, 1992, p. 283).
} 
própria filosofia política ${ }^{3}$. Arendt critica a filosofia política que desde Platão busca um lugar seguro para a imprevisibilidade própria da ação humana, que não reconhece a pluralidade e a capacidade humana de iniciar algo novo na continuidade do tempo e, por isso, não entende a política como o espaço entre-os-homens. A atividade da ação não fornece nenhuma certeza nem garantia. $\mathrm{O}$ mínimo de estabilidade é fornecido pela promessa e pelo perdão; promessa travada entre aqueles que participam da ação; perdão, quando o prometido não foi possível realizar. No texto Filosofia e política, Arendt esclarece que "foi a filosofia, a preocupação com a verdade independente dos assuntos humanos, que afastou seus adeptos da polis, tornando-os desajustados" (Arendt, 1993b, p. 94). A tradição da filosofia política, que vai de Platão até Marx, tenta repetidamente apresentar um plano teórico que pudesse orientar a ação humana. Não por acaso compreende política como governo (Arendt, 1993b, p. 114), em que alguns poucos têm o mando e a maioria deve obediência. No texto $A$ tradição e a época moderna, contido no livro Entre o passado e o futuro, Arendt explica que:

A Filosofia Política implica necessariamente a atitude do filósofo para com a Política; sua tradição iniciou-se com o abandono da Política por parte dos filósofos, e o subsequente retorno deste [sic] para impor seus padrões aos assuntos humanos. O fim sobreveio quando um filósofo repudiou a Filosofia, para poder "realizá-la na política". [...] Nossa tradição de pensamento político começou quando Platão descobriu que, de alguma forma, é inerente à experiência filosófica repelir o mundo ordinário dos negócios humanos; ela terminou quando nada restou dessa experiência senão a oposição entre pensar e agir, que, privando o pensa-

\footnotetext{
${ }^{3}$ Verificar os textos de Arendt: "Filosofia e política", "Só permanece a língua materna", "O interesse pela política no recente pensamento filosófico europeu", contidos no livro A dignidade da política (1993). A entrevista "Só permanece a língua materna" também está publicado em Compreender: Formação, exilio e totalitarismo (2008) com o título "OO que resta? Resta a língua': uma conversa com Günter Gaus". Verificar igualmente o texto "A tradição e a época moderna", contido no livro Entre o passado e o futuro (1992).
} 
mento de realidade e a ação de sentido, torna a ambos sem significado (Arendt, 1992, p. 44/52).

Arendt compreende a política como espaço entre-os-homens, como espaço da pluralidade; espaço onde os seres humanos aparecem uns aos outros quando agem e discursam; espaço onde a pluralidade humana encontra significação e a liberdade lugar. Arendt é taxada de utópica ao ir às origens das atividades da condição humana e chegar à Grécia antiga e a delimitação dos domínios público e privado. É criticada por sua compreensão de política, dizem ser irrealizável e não servir para nada, isto porque valoriza a atividade da ação; a ação não produz nada material como o faz o operário da fábrica; não permite mando e obediência como é o caso do lar em que há hierarquia. A incompreensão encontra-se na concepção de filosofia política adotada, no desejo de solidez e na incredulidade em relação à capacidade de ação inerente aos seres humanos na qual só há possibilidades. Para Arendt o significado da política é a liberdade 4 . Esta, porém, só pode ser esperada como se espera por milagres, isto é, sem certezas, sem saber se as consequências das ações livres serão boas ou terríveis. É apenas uma aposta na manutenção do mundo e na responsabilidade por ele. O preço pago pela liberdade é a imprevisibilidade, a incerteza, mas parece que continua a ser a opção mais indicada frente à dominação. Em "Será que a política ainda tem de algum modo um sentido?" - publicado inicialmente no Brasil no livro A dignidade da política e, posteriormente, no livro Que é política - Arendt argumenta:

Se o sentido da política é a liberdade, então isso significa que nós, nesse espaço, e em nenhum outro, temos de fato o direito de ter a expectativa de milagres. Não porque acreditamos [religiosamente] em milagres, mas porque os homens, enquanto puderem agir, são aptos a realizar o impro-

${ }^{4}$ Sobre o conceito de liberdade em Arendt verificar os importantes livros de Sônia Schio (2006) e Francisco Xarão (2000). Sobre o sentido da política em Arendt, verificar o livro de Iltomar Siviero (2008). 
vável e o imprevisível, e realizam-no continuamente, quer saibam disso, quer não (Arendt, 1993b, p. 122).

Arendt estabelece distinções ${ }^{5}$, busca as origens ${ }^{6}$ sem saudosismos improdutivos; a narrativa é seu estilo mais caro. Arendt quer examinar o presente, o mundo do qual faz parte e pelo qual se sente responsável; no entanto, não descarta o passado, pois este pode iluminar o presente. Ela não pode ser enquadrada em molduras $^{7}$, não pertence a esta ou aquela corrente de pensamento, não se ajusta aos padrões comuns da ortodoxia filosófica. Arendt não tem receio de examinar e reexaminar, de perceber as várias derivações de uma mesma questão ${ }^{8}$, de erguer perguntas, de ir além das polarizações, de pensar por ela mesma. Ela não quer ditar teorias, construir escola ou dizer o que se deve fazer (Arendt, 2010a, p. 132); não lhe cabe a figura arrogante do filósofo que profere verdades ou do doutrinador que prescreve ações. Talvez disto derive o brilhantismo, não só de A condição humana, mas dos demais escritos de Arendt. Arendt ousa ir além da segurança do lugar comum. Não por acaso, A condição humana foi escolhida e classificada no $5^{\circ}$ lugar dos 100 Livros do Século segundo o jornal parisiense Le Monde. Com certeza Arendt não teria se preocupado

\footnotetext{
${ }^{5} \mathrm{O}$ exemplo disto pode ser visto nas atividades da vida ativa - trabalho, obra, ação -, cada uma delas é analisada e reconstruída por meio de uma análise histórica que as distingue e que, ao mesmo tempo, as une. Outro exemplo é distinção entre liberdade e libertação contidas no livro Da revolução (1990).

${ }^{6}$ Arendt, além de filosofia, estudou filologia e estava apta a buscar as origens dos termos e dos conceitos. Deste modo, recorrer ao mundo grego antigo não é pregar o retorno helênico, não se trata de grecomania, como foi tão bem pontuado por Jacques Taminiaux (2002; 2008).

${ }^{7}$ Verificar a resposta de Arendt quando é perguntada se é conservadora ou liberal na transcrição do debate ocorrido entre Arendt e vários intelectuais num Colóquio em Toronto em 1972 intitulado "Sobre Hannah Arendt" (Arendt, 2010a, p. 156-157).

${ }^{8} \mathrm{O}$ exemplo disto pode ser percebido na análise do conceito Vida Ativa, como foi compreendido pelos gregos, pelos romanos, pelos medievais, etc. e como se fixou.
} 
com isso, pois fama não era o que buscava no mundo. Não por acaso, seu pensamento permanece vivo e a provocar o seu leitor. Arendt quer compreender (1993b, p. 39-53); em A condição humana quer compreender o que estamos fazendo no mundo.

\section{A condição humana e seus propósitos}

A riqueza da reflexão exposta em $A$ condição humana e, igualmente, os desafios da apreensão dos objetivos do escrito de Arendt são evidenciados a partir do prólogo. No entanto, o prólogo parece deslocado da estrutura e dos conceitos apresentados nos capítulos que o seguem e o leitor é levado a se perguntar: o que Arendt almeja realizar em $A$ condição humana? Qual é o pano de fundo das suas indagações? Quais são suas motivações? Qual propósito estabelece? Qual é o tema a guiar sua reflexão? Qual o método que orienta a elaboração do escrito? Qual a ligação com a obra completa de Arendt? O que a obra pode ainda dizer? Estas são as pergunta que se aspira esclarecer daqui adiante.

Aparentemente há uma fragilidade na estrutura proposta por Arendt em A condição humana. Parece que falta continuidade entre o prólogo e os capítulos - I A condição humana, II Os domínios público e privado, III Trabalho, IV Obra; V Ação - e entre aqueles e o capítulo final, que estabelece uma crítica à era moderna e à alienação - VI Vita activa e a era moderna. Arendt não é obtusa, seu propósito não é escrever um tratado de filosofia política que glorifique a ação, mas estabelecer distinções, a partir do mundo pensá-lo". "Não acredito que possa existir nenhum processo de

\footnotetext{
${ }^{9}$ Quando Arendt escreveu A condição humana não era definitivo para ela o lugar do pensar na atividade política, ainda estava muito influenciada por Heidegger e o curso sobre o Sofista; ao final da obra ela (Arendt, 2010b, p. 406) aponta para a atividade do pensar; era necessário o segundo livro sobre a Condição humana; é em $A$ vida do espírito (1995) que isto ficará claro, isto é, que o pensamento é experiência de pura atividade, pensar não é agir, mas é atividade. Verificar os textos " $O$ que resta? Resta a língua': uma conversa com Günter Gaus", no livro Compreender: formação, exílio e totalitarismo (2008), e "Sobre Hannah Arendt" (2010a).
} 
pensamento sem experiências pessoal. Todo pensamento é um pensamento posterior, isto é, uma reflexão sobre algum fato ou assunto (Arendt, 2008, p. 50). Deste modo, aquilo que parece à primeira vista carente de uma linha de continuidade é, com certeza, um esplêndido exercício de reflexão; reflexão sem guias a orientar previamente o ponto de chegada, reflexão livre, reflexão radical que permite olhares diversos. O maior desafio e também o mais encantador de $A$ condição humana é a possibilidade de ir e vir por suas páginas repetidamente, em momentos distintos, e ainda assim se surpreender.

Arendt remete o leitor a dois eventos de grande relevância: o lançamento do Satélite Sputnik na órbita terrestre pelos Russos em 1957 e o advento da automação. O primeiro revela de imediato o alto desenvolvimento da técnica e da ciência ${ }^{10}$. A Terra - natureza - não é mais o limite. O ser humano, capaz de criar um mundo artificial de coisas mundanas, rompe definitivamente o laço com a natureza e a própria vida pode ser criada artificialmente. Isto é significativo no contexto pós Segunda Grande Guerra e em plena Guerra Fria, uma vez que a destruição total da vida orgânica na Terra configura-se como plenamente realizável. Tal perspectiva foi confirmada aos homens e mulheres que habitam o mundo após a demonstração real da capacidade de destruição de toda a vida no planeta - bombas atômicas lançadas nos dias 6 e 9 de agosto de 1945 sob as cidades japonesas de Hiroshima e Nagasaki. A partir da consciência do poder das armas atômicas, gesta-se um grande temor, que passa a ser a base para a tomada de decisões em todos os âmbitos, ou seja, pesa drasticamente na vida das pessoas e nos vários Estados-nacionais. O satélite lançado, que nada mais é do uma obra humana, trouxe esperança: talvez se pudesse encontrar no universo uma nova morada para o ser humano e fosse possível recriar a própria vida sob meios não naturais. Todavia, a partir de

\footnotetext{
${ }^{10}$ Verificar o texto "A conquista do espaço e a estatura humana" contido no livro Entre o passado e o futuro (1992).
} 
uma análise mais aprofundada, a possibilidade de evadir a Terra por meio de um objeto fabricado pelo ser humano evidencia a contraposição entre tecnologia e natureza. A natureza não reina absoluta e o ser humano não mais está submetido a ela, ao contrário assume o poder sobre a natureza. A pergunta que se coloca é: quais serão as consequências desse avanço tecnológico e do poder da ciência e da tecnologia? O que Arendt aponta criticamente é que a discussão não se limita à ciência, é uma discussão política, pois diz respeito a todas as pessoas; no entanto, a ciência se mostra inapta para discutir politicamente o que é capaz de produzir (Arendt, 2010, p. 4).

O segundo evento, o da automação, igualmente resultante do desenvolvimento da ciência e da técnica, se tornou a mais nova experiência da sociedade moderna e atingiu diretamente seu modo de produção. A automação de pronto assinala para a possibilidade de liberar, definitivamente, o ser humano das agruras do trabalho e da necessidade, libertação esta que se busca desde tempos antigos. Todavia, a sociedade em que se está inserido é constituída como a sociedade dos trabalhadores; a identidade que cada membro dela possui é a de trabalhador. Com a automação, o que seria deste indivíduo? Arendt (2010b, p. 5-6) assinala que não restaria nada, pois não haveria trabalho, o que representa uma grande contradição em uma sociedade de trabalhadores.

Assim, o temor de destruição da vida orgânica na Terra e o advento da automação fazem vir à tona outras questões, que vão além da técnica, da ciência ou da administração. Questões que envolvem o âmbito das decisões públicas, que dizem respeito ao mundo humano, mundo que se encontra diante de uma nova e desconhecida era. Trata-se, portanto, de decisões que dizem respeito às escolhas e ao destino da humanidade inteira. Tais decisões não dependem única e exclusivamente do conhecimento técnico ou da administração. Além disto, técnica e ciência se mostraram inábeis para a resolução de tais questões. Não se trata da arte de governar ou de como fazer alguma coisa, não é techné ou poiéses. 
Não se trata de escolhas autocráticas ou de exclusividade dos políticos profissionais - governos etc. -, mas se refere ao domínio público, domínio em que todos os seres humanos estão implicados. Quando as questões e discussões dizem respeito a todos e ao destino da própria humanidade ${ }^{11}$, cada ser humano é igualmente capaz de apresentar seus pontos de vista e posicionamentos em meio aos demais, isto é, a discussão e a decisão se tornam políticas. Há, todavia, um problema: a era moderna, "que começa no século XVII e termina no limiar do século XX" (Arendt, 2010b, p. 7), subverteu a importância e a especificidade das atividades humanas e embaralhou a própria compreensão de cada uma das atividades: apenas uma delas reinou absoluta sobre as demais. É neste contexto que os temores e as novas experiências tornaram-se o pano de fundo político - porque dizem respeito ao mundo comum - que permite a Arendt estabelecer a necessidade de se reconsiderar a condição humana e as atividades humanas, descrevê-las e apresentar aquilo que é próprio de cada uma, no sentido de dirimir as confusões e imprecisões.

O prólogo expõe que o propósito de Arendt é provocar e animar a reflexão, suscitar perguntas, um pouco aos moldes daquele sujeito irritante - ele mesmo - que acompanha Sócrates quando ele abandona a ágora e retorna para casa, conforme descrito no Hipias Maior (Platão, 2007); o pensamento que volta para si mesmo para ruminar o próprio mundo e as experiências vividas nele, do qual retirou o material do pensamento. Arendt se propõe a realizar um exercício de pensamento ${ }^{12}$ em um mundo habitado por seres humanos que carecem de ação, reflexão e compreensão, pois estão absortos - alienadas ${ }^{13}$ - em si mesmos e nos processos biológicos de produção e consumo. No texto "O conceito de história:

\footnotetext{
${ }^{11}$ Sobre o tema verificar o livro de Odílio Alves Aguiar (2009).

12 Para aprofundar a discussão verificar o excelente livro de Bethania Assy (2015).

${ }^{13}$ Verificar o livro de Rodrigo Ribeiro Alves Neto (2009), que tratou com maestria da alienação do mundo em Arendt.
} 
antigo e moderno", contido no livro Entre o passado e o futuro, Arendt explica:

A época moderna, com sua crescente alienação do mundo, conduziu a uma situação em que o homem, onde quer que vá, encontre apenas a si mesmo. [...] Na situação de radical alienação do mundo, nem a história nem a natureza são em absoluto concebíveis. Essa dupla perda do mundo - a perda da natureza e a perda da obra humana no senso mais lato, que incluiria toda a história - deixou atrás de si uma sociedade de homens que, sem um mundo comum que a um só tempo os relaciona e separa, ou vivem em uma separação desesperadamente solitária ou são comprimidos em uma massa. Pois uma sociedade de massa nada mais é que aquele tipo de vida organizada que automaticamente se estabelece entre seres humanos que se relacionam ainda uns aos outros mas perdem o mundo outrora comum a todos eles (Arendt, 1992, p. 126).

Em A condição humana Arendt apresenta criticamente o ser humano que se perdeu na urgência metabólica da garantia da própria vida dia após $\operatorname{dia}^{14}$. Um ser humano que faz prevalecer no mundo público seus interesses privados, que não se preocupa com a permanência do mundo ${ }^{15}$ enquanto marco civilizatório, que abandona o mundo e fecha-se em si mesmo: um ser humano em completa solidão. $\mathrm{O}$ eu - self - de A condição humana está absorto em si mesmo e apartado do mundo. Este ser humano não compreende que o que há de comum entre os homens é o mundo e não suas necessidades. Em entrevista a Günter Gaus, Arendt esclarece:

[...] no trabalho e no consumo, o homem é totalmente lançado de volta para si mesmo. [...] Para o biológico e para si mesmo. E aí você tem o vínculo com a solidão. No processo de trabalho surge uma solidão peculiar. [...] essa solidão consiste em ser lançado de volta para si mesmo, um estado de coisas em que, por assim dizer, o consumo ocupa o lugar de todas as atividades realmente relacionais (Arendt, 2008, p. 50).

\footnotetext{
${ }^{14}$ O livro de Adriano Correia (2014) discute com profundidade essas questões. ${ }^{15}$ Verificar o texto de Arendt "A crise na educação" contido no livro Entre o passado e o futuro (1992). O livro de Vanessa Sievers de Almeida (2011) trata com rigor dos conceitos de Arendt.
} 
Na primeira grande obra de Arendt (1997) - Origens do Totalitarismo - encontra-se a hipótese de que o totalitarismo teria origem na atomização, na superfluidade e no desenraizamento dos seres humanos. O homem na modernidade abandonou o domínio público do mundo em favor da valorização da interioridade, desviando-se da perspectiva política da sua condição humana. Em regimes totalitários, não há espaço para a atividade política, mas somente para a submissão absoluta. Desta forma, qualquer ação deveria ser aniquilada, pois só existia espaço para a obediência passiva. Homens e Mulheres, nesse contexto, perdem a capacidade de discernir, de saber quem são. $\mathrm{O}$ mundo lhes é roubado. Em $A$ condição humana Arendt continua a tratar deste homem ${ }^{16}$.

$\mathrm{O}$ mundo ${ }^{17}$ tem duplo aspecto, pois ao mesmo tempo em que une, também separa. Une os seres humanos em torno de um tema que lhes é comum. Separa-os sob outras duas perspectivas: os seres humanos entre si e o ser humano e os processos naturais. O mundo separa os seres humanos entre si ao estabelecer uma distância imprescindível entre cada um, a distância que preserva a singularidade, que os distingue mesmo quando estão no domínio público. O mundo também separa o ser humano dos inevitáveis processos naturais de metabolismo e morte. O ser humano não se reduz à natureza, é animal laborans, ao mesmo tempo em que é homo faber, homem que fabrica e cria o mundo artificial de coisas que serve de morada, cria civilização. Ainda assim, o mundo enquanto artifício humano - é feito de muitos seres singulares e une novamente esses singulares quando eles se mostram aos demais por meio da ação e do discurso; além de animal laborans e homo faber somos homens e mulheres de ação e discurso. Outro aspecto torna-se importante: a revelação do "quem" cada um é somente é possível pela a ação; assim, sem o mundo não haveria revelação do próprio eu, da identidade própria de cada um, da

\footnotetext{
${ }^{16}$ André Duarte (2002) apresenta importante reflexão sobre esta temática.

${ }^{17}$ Verificar o livro de Fábio Abreu Passos (2014).
} 
singularidade. "O mundo não é a mesma coisa que as pessoas que o habitam. O mundo está entre as pessoas [...]" (Arendt, 1991, p. 12-13). A política tem caráter de revelação; deste modo, o capítulo $\mathrm{V}$ Ação de $A$ condição humana começa com uma seção sobre a revelação do agente no discurso e na ação. A disposição de mostrar-se é possível pela ação compartilhada de uma pluralidade de seres humanos. Sem a pluralidade não haveria o reconhecimento da personalidade de cada indivíduo. O contexto do reconhecimento é o domínio público.

Em carta a Jaspers ${ }^{18}$, Arendt confessa que ela mesma acabara de apreender a amar o mundo. "Comecei tão tarde, há apenas alguns anos, a amar verdadeiramente o mundo [...] Por gratidão, desejaria chamar ao meu livro de teoria política "Amor Mundi" (Arendt; Jaspers, 1992, p. 264). Talvez por isso Arendt tenha se interessado tanto por compreender o mundo ou, talvez, por compreendê-lo tenha aprendido a amá-lo. As duas alternativas podem ser válidas; todavia, o interessante é que Arendt tenha ofertado tantos escritos sobre o mundo e sobre o amor pelo mundo ${ }^{19}$. No Diário Filosófico, nota 55 do caderno XXI, datada de julho de 1955, Arendt escrevia:

Amor mundi: trata del mundo, que se forma como dimensión espacial y temporal tan pronto como los hombres están en plural; no hace falta que estén los unos con los otros, o los unos junto a los otros, basta la pura pluralidad (El puro entre) (Arendt, 2006, p. 524).

Para Arendt, aquele que se perde nos processos metabólicos perde simultaneamente a ligação com o mundo e com a pluralidade humana. A pluralidade é fundamental para Arendt. Ainda no Diário Filosófico, na nota 1 do caderno IV, que data de maio de 1951, Arendt, ao fazer referência à sociedade de trabalhadores de

${ }^{18}$ Carta $n^{\circ} 169$, de 6 de agosto de 1955, encontrada na Correspondência entre Hannah Arendt e Karl Jaspers (Arendt; Jaspers, 1992, p. 264).

${ }^{19}$ Para a biógrafa definitiva de Arendt, Elisabeth Young-Bruehl (1997), o tema unificador da obra completa de Arendt é o amor mundi. 
Marx, diz “[...] la sociedad no es más que la pluralidad, ordenada y organizada en cada caso de forma distinta. Desde Platón (hasta Heidegger) esta pluralidad es un obstáculo en el camino del hombre [...]." (Arendt, 2006, p. 79). O primeiro modo de pluralidade se encontra na ação quando se está com os demais: somos eu e os outros. Este eu é aquele que aparece no mundo mostrando-se como único, singular. Pode aparecer porque não se perdeu do mundo e não se reduziu a mero animal laborans. O segundo modo de pluralidade é quando se está consigo-mesmo; existe o eu e eu mesmo, trata-se do eu-comigo-mesmo das atividades da vida contemplativa $^{20}$. Embora este segundo modo de pluralidade seja fundamental, a única morada do ser humano é o mundo comum compartilhado por uma pluralidade de seres humanos. Para Arendt (2010b, p. 219), a pluralidade é a condição básica e a razão de ser da ação e do discurso. "[...] 'por que há os homens e não o Homem?', Kant teria respondido: a fim de que possam falar uns aos outros" (Arendt, 1993a, p. 54). Assim, a ausência de pensamento e de ação, este apartar-se de si mesmo e do próprio mundo, compõe as motivações apresentadas por Arendt à necessidade de se reconsiderar as atividades da condição humana sob nova perspectiva.

Paul Ricœur assinala que $A$ Condição humana constitui-se como um livro de resistência e de reconstrução. "A possibilidade do

\footnotetext{
${ }^{20}$ Há uma diferença entre o ego pensante - self - e o eu - self - que coabita todo ser humano que pensa -, o ser humano que é do mundo. O eu corresponde à mundanidade, uma vez que diz respeito ao conhecimento necessário para se lidar com as coisas do mundo, ou seja, o eu se envolve e se preocupa com os meios necessários para se viver no mundo. Além disso, o eu corresponde à individualização, à singularidade, àquilo que diferencia um ser humano do outro em um mundo de aparência, onde há outros seres singulares - o eu participa do mundo de aparência. O ego pensante - self - não possui qualquer impulso próprio para se mostrar em um mundo de aparências - fenomênico -, o impulso de se mostrar decorre do fato de o ser humano ser do mundo, de o mundo ser a sua morada. Do ponto de vista do mundo da aparência, ele é oculto, invisível. Verificar A vida do espírito (Arendt, 1995, p. 126).
} 
mundo não-totalitário deve ser buscada nos recursos de resistência e de renascimento contidos na própria condição humana" (Ricœur, 1983, p. 14; tradução livre). Resistência aos horrores descritos em Origens do totalitarismo, resistência ao total colapso da humanidade. É preciso reconsiderar as atividades humanas para que, ao reconhecer devidamente cada uma delas, seja possível resistir à dominação, principalmente ao se reconhecer a possibilidade de ação, resistir à submissão às condições naturais de existência ou a algum poder arbitrário. A partir disto, reconstruir a dignidade da política e do próprio ser humano como aquele de age e discursa em meio à pluralidade de seres hábeis em agir e discursar. Nas palavras de Arendt:

O que proponho nas páginas que se seguem é uma reconsideração da condição humana do ponto de vista privilegiado de nossas mais novas experiências e nossos temores mais recentes. É óbvio que isso é um assunto do pensamento, e a ausência de pensamento [thoughtlessness] a despreocupação negligente, a confusão desesperada ou a repetição complacente de "verdades" que se tornaram triviais e vazias - parece-me ser uma das mais notáveis características do nosso tempo. O que proponho, portanto, é muito simples: trata-se apenas de pensar o que estamos fazendo. "O que estamos fazendo" é, na verdade, o tema central deste livro. [...] o propósito final da análise histórica é o de rastrear até sua origem a moderna alienação do mundo, em sua dupla fuga da Terra para o universo e do mundo para o si-mesmo [self], a fim de chegar a uma compreensão da natureza da sociedade, como esta se desenvolvera e se apresentava no instante em que foi suplantada pelo advento de uma era nova e ainda desconhecida. (Arendt, 2010b, p. 6-7).

Mesmo que o prólogo do livro A condição humana atenda ao seu fim, isto é, delimitar o tema geral - o que estamos fazendo -, apresentar os objetivos - provocar e animar a reflexão, rastrear a origem da moderna alienação do mundo, reconsiderar a condição humana ao apresentar as atividades humanas elementares -, demarcar o método - análise histórica -, ainda assim, é possível encontrar, em outros escritos da autora e em correspondências trocadas, distintos elementos sobre o que Arendt se propõe a 
realizar. Jaspers (Arendt; Jaspers, 1992, p. 407), após realizar a leitura da obra Vita activa: oder von tätiger Leben (edição alemã de A condição humana), em carta de $1^{\circ}$ de dezembro de 1960, assinala à Arendt que o que ela havia estabelecido no prólogo como seu pano de fundo - o que estamos fazendo no mundo - não é retomado explicitamente em lugar algum do livro, mas percorre-o do começo ao fim e é justamente isto que o fascinou no livro. A análise de Jaspers mostra que os objetivos de Arendt são complexos. Isso, no entanto, não significa, de modo algum, qualquer tipo de desmerecimento a obra; ao contrário, confirma a profundidade do propósito de Arendt, o que leva à hipótese da relevância de se alinhavar A condição humana com outras obras de Arendt.

No projeto encaminhado por Arendt à Fundação Rockefeller em que buscava recursos para a elaboração de um livro de introdução à política, mais ou menos nos moldes da Introdução ao pensamento filosófico de Jaspers - pode-se encontrar uma descrição bem mais pontual do propósito do livro A condição humana: o livro trata de observações preliminares, prolegômenos. E, sem dúvida, esta é a perspectiva mais acertada do ponto de vista das obras completas de Arendt.

[...] a atividade política humana central é a ação; mas para se chegar a uma compreensão adequada da natureza da ação, mostrou-se necessário separar ação conceitualmente de outras atividades humanas, com as quais é confundida em geral, tais como trabalho [sic] e obra [sic]. Por isso, escrevi primeiro o livro que apareceu em 1958 com o título The human condition; ele trata de três importantes atividades humanas: trabalho [sic], obra [sic] e ação, em perspectiva histórica. Devia chamarse Vita Activa. Na verdade, é uma espécie de prolegômenos de um livro que tenciono escrever agora [Introdução à política]. Ele (isto é, o novo livro) continuará onde o outro livro termina. Em termos de atividades humanas, dirá respeito exclusivamente a ação e pensamento (Arendt, 2002, p. 197-198).

O fio que Arendt adota para conduzi-la na investigação é a análise histórica, pois não quer que lhe escape nada. Expõe que o 
propósito último do livro é realizar uma investigação histórica da origem da moderna alienação. Arendt entende que a história ${ }^{21}$ é uma narrativa que perpassa o tempo passado, presente e pode apresentar uma possível significação futura. A narração é a memória das ações realizadas, ações que enquanto em execução não se revelam, pois a revelação depende do espectador atento que pode contar o que sucedeu - após ter sucedido - perpetuando, deste modo, os atos e as palavras. Assim, as obras e os conceitos de Arendt sugerem os tempos passado, presente, futuro: Origens do totalitarismo remete ao passado, pergunta-se o que fizemos; $A$ condição humana, ao presente, pergunta-se o que estamos fazendo; $A$ vida do espírito, ao futuro, o que é possível fazer. Um dos livros que Arendt organizou com questões eminentemente políticas recebe o título Entre o passado e o futuro, isto é, um título que explicita que se trata de questões presentes. Quanto aos termos usados por Arendt, pode-se estabelecer as relações a seguir: o pensar remete ao presente, o que se sucede; a vontade, ao futuro, o que se almeja, o que se quer; o julgar, ao passado, pois se julga o que já aconteceu. $\mathrm{O}$ trabalho remete ao passado, o campo do necessário onde não há escolha; a obra, ao presente, ao que está materializado e fornece as condições para a ação; a ação, ao futuro, pois tudo poderia ser de outra maneira, não há certeza.

Arendt compreende que se deve examinar todos os pressupostos e em qualquer caso pensar criticamente ${ }^{22}$. A análise conceitual the causava apreço, queria compreender de onde derivavam os conceitos e investigava para isto a origem linguística. Interessavase pelos variados usos dos conceitos, como se desenvolveram, onde e de que modo se confundiram e se recriaram. No entanto, apenas o conceito não lhe era suficiente, também observava os feitos ou malfeitos dos seres humanos; por isso, os acontecimentos presen-

\footnotetext{
${ }^{21}$ Verificar o texto "O conceito de história - antigo e moderno", contido no livro Entre o passado e o futuro (1992).

${ }^{22}$ Palavra que Arendt não aprecia usar, para não ser confundida com os teóricos da Escola de Frankfurt (Arendt, 2010a, p. 131).
} 
tes e passados - a história da humanidade - lhe interessavam tanto; seus escritos estão inundados deles. Tais elementos que compõem o estilo da escrita de Arendt ou seu método permitem a muitos considerarem $A$ condição humana uma fenomenologia das atividades humanas.

Sem dúvida, Arendt apresenta em $A$ condição humana três atividades humanas básicas. O trabalho corresponde ao metabolismo, à vida biológica, à necessidade, trata-se do animal laborans. A obra corresponde à capacidade de criar artefatos e com eles dar permanência ao mundo, trata-se do homo faber que com suas mãos fabrica o artifício humano que diz respeito ao campo da utilidade. Arendt faz um diagnóstico da sociedade de trabalhadores e aponta criticamente para a falsa dignidade que ela possui, uma dignidade farsa, pois este trabalhador foi reduzido a mero produtor e consumidor voraz, cujo único propósito é consumir objetos de uso que rapidamente se deterioram. O preço pago por isto é a ruína do mundo, o artifício humano que traria durabilidade para o mundo não tem mais duração: vive-se na sociedade do descartável, descarta-se inclusive pessoas. Nem o tempo tem mais duração, o tempo é acelerado, é rápido. Como esta sociedade do tempo rápido e do consumo do descartável teria tempo para a política, uma vez que a política despende tempo de aparecimento, de apresentação, de ouvir o outro, de elaborar e reelaborar, em conjunto com outros, entre os outros. A ação corresponde à pluralidade humana, à atividade em que a singularidade e a distinção são garantidas. Todavia, não é possível reduzir o livro a uma descrição das atividades e a uma crítica das confusões que tais atividades sofreram. Arendt faz um diagnóstico abrangente da era moderna e a total alienação dos seres humanos, ao mesmo tempo em que apresenta a possibilidade de redenção pela ação. Arendt, ao descrever a atividade da ação, pontua que a política não corresponde a um fazer ou produzir, como é o caso do homo faber. Através disto ela critica a tradição da filosofia política como nenhum outro filósofo chegou a fazê-lo; uma tradição que ainda busca princípios abso- 
lutos e verdades, que mira a política a partir do ponto de vista da contemplação, desvinculada da ação. Além disto, Arendt não descreve a ação como um utópico campo onde reina a bondade e acertos; o caráter imprevisível e a liberdade presentes na ação podem gerar perigos, não há garantias de que os resultados da ação serão benéficos. Mesmo que a ação não possa fornecer certezas, há possibilidade do milagre em cada nova ação empreendida no mundo, pois cada ser humano nasce para começar, para trazer a novidade, para surpreender. Quem duvida disso?

\section{Relevância à guisa de considerações finais}

Não existe em Arendt qualquer plano de construção de sistema; contudo, pode-se aludir que reflexões suscitadas e enfrentadas em uma obra levam a outras questões. Deste modo, é possível estabelecer certas ligações ou mesmo complementaridades entre os vários escritos de Arendt. É neste sentido que se propôs alinhavar os conceitos de A condição humana com outros escritos de Arendt, principalmente a partir da crítica que ela dirige à tradição do pensamento político. Caso seja possível estabelecer um objetivo comum, um fio de ligação, entre as obras completas de Arendt, este pode ser pronunciado como a busca da dignidade da política. Arendt busca a dignidade da política ao perguntar pelo seu sentido apesar das impropriedades, malfeitos, horrores que fomos capazes de produzir enquanto seres humanos que habitam este planeta. Tem a política ainda algum sentido, apesar da radicalidade do mal que se cometeu quando o próprio ser humano foi tornado supérfluo enquanto ser humano, quando retirou-se dele a imprevisibilidade, a espontaneidade? Essas mazelas Arendt discutiu em 1951, em Origens do totalitarismo (1997), apresentou respostas à pergunta: o que fizemos no mundo? Pergunta retomada e ampliada, em 1963, em Eichmann em Jerusalém: um relato sobre a banalidade do mal (1999). A dignidade da política se encontra na atividade da ação, na liberdade própria a ela, na possibilidade da novidade, do começo, ligada à natalidade. Neste sentido, $A$ condi- 
ção humana oferece-se como fundamental, pois é nesta obra que Arendt revela a grandiosidade da ação diante das demais atividades - trabalho, obra. A ação é atividade independente, não se submete hierarquicamente às demais, nem às necessidades ou à utilidade. A política tem dignidade própria, uma vez que não é meio; constitui-se enquanto espaço entre-os-homens e garante a permanência do próprio mundo humano. Mas A condição humana não é um livro de filosofia política, é preparação - prolegômenos para questões políticas que serão tratadas por Arendt em obras como Entre o passado e futuro (1992), Da Revolução (1990), Sobre a violência (1994), Homens em tempos sombrios (1991) e Crises da República (2004).

Como acima, o prólogo de $A$ condição humana conduz ao esclarecimento que a questão principal - tema e propósito - de Arendt diz respeito à permanência ou não do mundo. Esta questão ainda traz inquietações, sua atualização repercute e mostra-se relevante. As mesmas perturbações - temores e experiências - que Arendt apresenta como comuns aos seus contemporâneos sobre a permanência da vida orgânica na Terra podem ser atualizadas e ampliadas: a vida orgânica na Terra será destruída? Sob quais condições e em que termos o cientista pode criar a vida? Que mundo será deixado para as futuras gerações? É possível encontrar formas menos predatórias de conviver com as outras espécies que também habitam o planeta ou o ser humano devastará tudo com sua insaciável voracidade? O respeito à dignidade da pessoa humana é um valor importante para conduzir a tomada de decisões? O ser humano quer participar das decisões que dizem respeito ao mundo comum ou preferem a alienação? Estas e muitas outras perguntas que podem ser formuladas pertencem ao campo da política e a resposta deve ser dada a partir do espaço público do mundo. A resposta só pode ser encontrada no espaço da política; a resposta é política, pois depende de todos, uma vez que implica todos. Apesar disto, não temos garantias de que qualquer ação será iniciada. Revelam-se a atualidade e a pertinência da pergunta principal de $A$ 
condição humana 60 anos após sua publicação: o que estamos fazendo no mundo?

No Brasil, são muitos os pesquisadores e as pesquisadoras que se dedicam à obra de Hannah Arendt. Tais pesquisas foram intensificadas nas últimas duas décadas, o que conduziu a obra completa de Arendt à grande relevância no cenário nacional. Destacam-se, entre tantos outros: Adriano Correia (UFG), Andre Duarte (UFPR), Bethania Assy (UERJ e PUC-Rio), Celso Lafer (USP), Claudia Perone Moisés (USP), Claudio Boeira Garcia (UNIJUÍ), Christina Miranda Ribas (UEPG), Edson Teles (UNIFESP), Eduardo Jardim (PUC-Rio), Fábio Abreu dos Passos (UFPI), Francisco Xarão (UNIFAL), Iltomar Siviero (IFIBE), José Luiz de Oliveira (UFSJ), José Sergio Fonseca de Carvalho (USP), Newton Bignotto (UFMG), Odílio Alves Aguiar (UFC), Rodrigo Ribeiro Alves Neto (UniRio), Silvana Terezinha Winckler (Unochapecó), Sônia Maria Schio (UFPel), Maria Theresa Vaz Calvet de Magalhães (UFMG), Vanessa Sievers de Almeida (UFBA).

Celso Lafer foi o grande responsável pela introdução dos escritos de Arendt no país. Conseguiu autorização da própria Arendt para a publicação, em 1972, por sugestão dela, da obra Entre o passado e futuro e a esta se seguiu várias outras. Hoje, grande parte das obras de Arendt encontra-se traduzida e publicada em língua portuguesa, com exceção de artigos, correspondências e outros escritos que não foram publicados pela própria Arendt, mas compõe seu espólio. Adriano Correia pertence à geração de pesquisadores de Arendt que sucedeu a Celso Lafer. Sua pesquisa iniciou na década de 1990 e constitui-se uma das grandes referências em Arendt no Brasil, principalmente após a revisão da tradução da obra $A$ condição humana. A mudança mais pertinente foi a alteração dos termos labor e trabalho, proposta por Arendt como trabalho e obra, uma vez que há uma distinção clara entre estes termos. A necessidade desta alteração havia sido pontuada e repetida por Teresa Calvet Magalhães (2002, p. 10-11) desde a primeira edição de $A$ condição humana no Brasil, por isso a relevância da 
revisão da tradução. A apresentação redigida por Correia (2010, p. XIII-XLIV) a revisão deve ser incluída como bibliografia básica para o estudo de $A$ condição humana.

$\mathrm{O}$ incremento das gerações de pesquisadores da obra de Arendt no Brasil continua a passos largos e inúmeras são as dissertações, teses, e mesmo trabalhos de conclusão de cursos defendidos nas últimas duas décadas, tendo Arendt como referência principal. Mesmo que não exista uma estatística sobre o assunto, é possível asseverar pela observação e experiência docente que o interesse dos estudantes e pesquisadores se multiplica. Inúmeros eventos acadêmicos $^{23}$ com o objetivo de disseminar a produção acadêmica sobre Arendt acontecem todos os anos nas universidades brasileiras, todos com um público significativo, composto por representantes de variadas áreas do conhecimento, e produção qualificada. Não porque Arendt seja mais uma autora "da moda", mas porque seus escritos permanecem atuais e aludem reflexões e novas perguntas.

\section{Referências}

AGUIAR, Odílio Alves. Filosofia, política e ética em Hannah Arendt. Ijuí: UNIJUÍ, 2009.

ALMEIDA, Vanessa Sievers de. Educação em Hannah Arendt: entre o mundo deserto e o amor pelo mundo. São Paulo: Cortez, 2011.

\footnotetext{
${ }^{23}$ Apenas para citar alguns: Encontro Internacional Hannah Arendt, está na $11^{\mathrm{a}}$ edição, evento itinerante; Ciclo Hannah Arendt (UEL); Encontro Hannah Arendt (UVA); Encontro Nacional de Filosofia Política Contemporânea, está na $3^{\mathrm{a}}$ edição e conta com inúmeros participantes que fundamentam suas pesquisas em Arendt; Simpósio Hannah Arendt (UFSC); Colóquio Hannah Arendt (USP).
} 
ALVES NETO, Rodrigo Ribeiro. Alienações do mundo: uma interpretação da obra de Hannah Arendt. Rio de Janeiro: PUC-Rio; São Paulo: Loyola, 2009.

ASSY, Bethania. Ética, responsabilidade e juízo em Hannah Arendt. São Paulo: Perspectiva; Instituto Norberto Bobbio, 2015.

ARENDT, Hannah. Condition de l'homme moderne. Trad. Georges Fradier. Paris: Calmann-Lévy, 1983.

ARENDT, Hannah. Da revolução. 2. ed. Trad. Fernando Dídimo Vieira. São Paulo: Editora Ática; Brasília: UnB, 1990.

ARENDT, Hannah. Homens em tempos sombrios. Trad. Ana Luísa Faria. Lisboa: Relógio D'Água, 1991.

ARENDT, Hannah. Entre o passado e o futuro. 3. ed. Trad. Mauro W. Barbosa de Almeida. São Paulo: Perspectiva, 1992.

ARENDT, Hannah. Lições sobre a filosofia política de Kant. Trad. André Duarte de Macedo. Rio de Janeiro: Relume-Dumará, 1993a.

ARENDT, Hannah. A dignidade da política: ensaios e conferências. Trad. Helena Martins. Rio de Janeiro: Relume-Dumará, 1993b.

ARENDT, Hannah. La condicion humana. Trad. Ramón Gil Novales. Barcelona; Buenos Aires; México: Paidós, 1993c.

ARENDT, Hannah. Sobre a violência. Trad. André Duarte. Rio de Janeiro: Telume-Dumará, 1994.

ARENDT, Hannah. A vida do espírito: o pensar, o querer, o julgar. 3. ed. Trad. Antonio Abranches, César Augusto R. de Almeida e Helena Martins. Rio de Janeiro: Relume-Dumará, 1995. 
ARENDT, Hannah. Origens do Totalitarismo: anti-emitismo, imperialismo, totalitarismo. Trad. Roberto Raposo. São Paulo: Companhia das Letras, 1997.

ARENDT, Hannah. Eichmann em Jerusalém: um relato sobre a banalidade do mal. Trad. José Rubens Siqueira. São Paulo: Companhia das Letras, 1999.

ARENDT, Hannah. O que é política? 3. ed. Trad. Reinaldo Guarany. Rio de Janeiro: Bertrand Brasil, 2002.

ARENDT, Hannah. Diario filosófico: 1950-1973. Barcelona: Herder, 2006.

ARENDT, Hannah. Compreender: Formação, exílio e totalitarismo. Ensaios (1930-1954). Trad. Denise Bottmann. São Paulo: Cia. das Letras, 2008.

ARENDT, Hannah. Sobre Hannah Arendt. Trad. Adriano Correia. Revista inquietude. Goiânia, v. 1, n. 2, ago.-dez, 2010a, p. 123-163.

ARENDT, Hannah. A condição humana. 11. ed. Trad. Roberto Raposo. Revisão e Apresentação de Adriano Correia. Rio de Janeiro: Forense Universitária, 2010b.

ARENDT, Hannah. A condição humana. 13. ed. rev. Revisão de Tradução Adriano Correia, Introdução de Margaret Canovan. Rio de Janeiro: Forense Universitária, 2016.

ARENDT, Hannah; JASPERS, Karl. Hannah Arendt - Karl Jaspers: Correspondence 1926-1969. Ed. Lotte Kohler and Hans Saner. Transl. from German Robert and Rita Kimber. San Diego; New York; London: Harvest Book, 1992.

CANOVAN, Margaret. Introdução. In: ARENDT, Hannah. A condição humana. 13. ed. rev. Revisão de Tradução Adriano Correia, introdução de Margaret Canovan. Rio de Janeiro: Forense Universitária, 2016. p. LILXVII. 
CORREIA, Adriano. Apresentação à nova edição brasileira de $A$ condição humana. In: ARENDT, H. A condição humana. 11. ed. Trad. Roberto Raposo. Revisão e Apresentação de Adriano Correia. Rio de Janeiro: Forense Universitária, 2010. p. XIII-XLIV.

CORREIA, Adriano. Hannah Arendt e a modernidade: política, economia e a disputa por uma fronteira. Rio de Janeiro: Forense Universitária, 2014.

DUARTE, André. Hannah Arendt e a modernidade: esquecimento e redescoberta da política. In: CORREIA, Adriano. (Org.). Transpondo o abismo: Hannah Arendt entre a filosofia e a política. Rio de Janeiro: Forense, 2002. p. 55-78.

LAFER, Celso. A política e a condição humana (Posfácio). In: ARENDT, Hannah. A condição humana. Trad. Roberto Raposo. Rio de Janeiro: Forense Universitária, 1981. p. 340-351.

MAGALHÃES, Teresa Calvet de. Hannah Arendt e a desconstrução fenomenológica da atividade de querer. In: CORREIA, Adriano. (Org.). Transpondo o abismo: Hannah Arendt entre a filosofia e a política. Rio de Janeiro: Forense, 2002. p. 10-31.

PASSOS, Fábio Abreu. O conceito de mundo em Hannah Arendt: para uma nova filosofia política. Rio de Janeiro: Lumen Juris, 2014.

PLATÃO. Diálogos II: Górgias, Eutidemo, Hipias Maior, Hipias Menor. São Paulo; Bauru: Edipro, 2007.

RICOEUR, Paul. In: ARENDT, Hannah. Condition de l'homme moderne. Trad. Georges Fradier. Paris: Calmann-Lévy, 1983. p. 5-32.

SCHIO, Sônia Maria. Hannah Arendt: história e liberdade (da ação à reflexão). Caxias do Sul: EdUCS, 2006.

SIVIERO, Iltomar. Sentido da política: estudo em Hannah Arendt. Passo Fundo: IFIBE, 2008. 
TAMINIAUX, Jacques. Athens and Rome. In: VILLA, Dana. The Cambridge companion to Hannah Arendt. New York: Cambridge University Press, 2002. p. 165-177.

TAMINIAUX, Jacques. ¿'Perfomatividad' y 'grecomanía'? In: BIRULÉS, Fina et al. Hannah Arendt: el legado de una mirada. Madrid: Sequitur, 2008. p. 84-98.

XARÃO, Francisco. Política e liberdade em Hannah Arendt: ensaio sobre a reconsideração da vita activa. Ijuí: UNIJUÍ, 2000.

YOUNG-BRUEHL, Elisabeth. Por amor ao mundo: a vida e a obra de Hannah Arendt. Trad. Antônio Trânsito. Rio de Janeiro: Relume-Dumará, 1997.

Artigo recebido em 2/05/2018, aprovado em 16/05/2018 